\title{
A REPRESENTAÇÃO DO NEGRO NA POESIA AFRO-BRASILEIRA CONTEMPORÂNEA DE CUTI
}

\section{THE BLACK REPRESENTATION IN CUTI'S CONTEMPORARY AFRO- BRAZILIAN POETRY}

\author{
Simone de Castro Assumpção ${ }^{1}$ \\ Rosidelma Pereira Fraga ${ }^{2}$
}

RESUMO: A poesia afro-brasileira surge no momento em que o afrodescendente assume a posição de sujeito da enunciação. Ao tomar posse da palavra, o descendente de africano revela um "existir negro" no seu modo de ver e sentir o mundo, por meio de um eu-enunciador-que-se-quer-negro e que contesta os valores representados pela cultura dominante, além de mostrar os aspectos da sociedade não revelados pela literatura instituída. Nesses escritos, também chamados de contraliteratura, por promoverem a ruptura com a escrita ditada pelos brancos, o poeta não fala somente em seu nome. Nessa perspectiva, o escritor é o porta-voz de sua etnia e, portanto, afirma sua condição de negro. Ao mesmo tempo, busca uma identidade para representá-lo em sua poesia, visto que a procura de uma identidade negra é a característica fundamental da poesia afro-brasileira. Dentre esses poetas afrobrasileiros, encontra-se o autor Cuti (2011), cuja poesia será objeto de estudo nesse artigo, no sentido de compreender como esse poeta constrói a identidade negra nos seus escritos. Para atingir esse objetivo, identificaremos os elementos a que o poeta recorre para construir essa identidade. Também verificaremos os procedimentos adotados por esse escritor para afirmar a identidade negra e posteriormente analisaremos os recursos utilizados pelo autor para combater os estereótipos atribuídos ao negro pelo branco. Para isso, recorremos às pesquisas realizadas por Ianni (1988), Bernd (1988), Duarte (2005) e Cavalcante (2017) sobre a literatura negra; Bento (2002) e Munanga (2006) sobre preconceito racial, e também aos estudos realizados por Hall (1996) a respeito das identidades e aos escritos de Cuti (2011).

Palavras-chave: Poesia, Negro, Identidade, Denúncia, Combate.
ABSTRACT: Afro-Brazilian poetry arises when the Afro-descendants take over the position of subjects of enunciation. In taking possession of the word, the African descendants reveal a "black existence" in their way of seeing and feeling the world, through a black-self-enunciator-whodesires-him/herself-as-a-black and that challenges the values represented by the dominant culture, besides showing the aspects of society not revealed by the canonical writings. In these writings, also called contraliteratura, for promoting the rupture with the writing dictated by whites, the poets do not speak on behalf of themselves. From this perspective, the writer is the spokesperson for his/her ethnicity and therefore affirms his/her status as a black person. At the same time the poets seek an identity to represent themselves in their poetry, being that the search for a black identity is the fundamental characteristic of Afro-Brazilian poetry. Cuti(2011) is among those Afro-Brazilian poets whose poetry will be the object of study in this article, in the sense of understanding how he builds the black identity in his writings. To reach this goal we will identify the elements that the poet uses to construct this identity. Also we will verify the procedures adopted by this writer to affirm the black identity and later we will analyze the resources used by the author to fight the stereotypes attributed to the black by the white. For this, we used the researches done byIanni (1988), Bernd (1988), Duarte (2005) and Cavalcante (2017) on black literature; Bento (2002) and Munanga (2006) on racial prejudice and alsostudies by Hall (1996) about the identities and Cuti's (2011) writings.

Keywords: Poetry, Black, Identity, Complaint, Fight.

\footnotetext{
1 Professora egressa do Curso de Especialização em Língua Portuguesa e Literatura da UERR. Trabalho defendido em 2018. 2 Prof ${ }^{a}$ Doutora em Literatura. Colaboradora do Curso de Especialização em Língua Portuguesa e Literatura na UERR e orientadora desta pesquisa. Professora de Literatura e Língua Portuguesa na UFRR.
} 


\section{INTRODUÇÃO}

A figura do negro sempre esteve presente na literatura brasileira, desde o período préabolicionista até o contemporâneo. No entanto, no período escravocrata e, mesmo décadas após a abolição da escravidão, 0 negro era o tema, o assunto da poesia. Nessa literatura, tínhamos a visão do outro sobre essa população. Essa visão, não raramente, apresentava distorções e estereótipos.

No período escravocrata, o negro era o cativo do qual todos se condoíam dos seus sofrimentos. Os dramas da escravidão eram retratados sob a perspectiva exterior. Com a abolição da escravidão, o ex-cativo é forçado a ir para a área urbana e, como não possui qualificação profissional sofre um rápido processo de marginalização que dá origem à imagem estereotipada do afrodescendente na sociedade.

Neste sentido, percebemos que o exescravo é visto como o malandro, amoral, preguiçoso, dentre outros estereótipos atribuídos à imagem do descendente de africanos. Porém, poderia ocorrer a "regeneração da raça", se o negro aderisse à ideologia do branqueamento, pois "a crença de que só o assumir dos costumes, da moral e da cultura do branco, dará ao afrodescendente condições de ascensão social determina um processo de alienação, de afastamento progressivo dos valores culturais do mundo negro“ (Bernd, 1988, p. 62). Com base neste pensamento crítico, ocorre na poesia a tentativa de "embranquecer" o afrodescendente, negando, assim, a sua identidade negra. Há, ainda no período pós-abolicionista, o olhar do outro sobre essa etnia.

Entretanto, na década de 70, surgiram movimentos negros articulados que se ocuparam de denunciar o racismo, a discriminação e a marginalização sofridos por essa população. Também reivindicavam o direito à diferença, ao reconhecimento da identidade e ao exercício da plena cidadania desse grupo étnico. Motivados por esses movimentos articulados, cresceu a produção de escritores negros que em suas poesias tomam a posição de sujeitos da enunciação, reescrevem a História do seu ponto de vista e buscam afirmar sua identidade negra, sendo esta a característica fundamental da poesia afro-brasileira.Nesse contexto, destacamos a presença de $\mathrm{Cuti}^{3}$, poeta, dramaturgo, ensaísta e ficcionista. Atua na criação, na crítica e no trabalho político-cultural junto à comunidade afro-brasileira. Cuti foi membro do grupo Quilombhoje Literatura, organizando os volumes da série Cadernos Negros. Também atuou no Jornegro e organizou várias edições do Feconezu Festival comunitário negro Zumbi. A poesia de Cuti contribui para revelar os problemas essenciais do negro brasileiro, ainda vítima de preconceito e discriminação, além de buscar uma identidade negra para representar o seu grupo étnico, construída sob a ótica negra.

Essa literatura defendida acima, na qual o negro é protagonista de sua história, faz parte da literatura brasileira, que é formada não apenas pelos textos considerados canônicos, sendo constituída pela escrita de vários povos. No entanto, apesar da Lei 11.645/2008, que determina que a disciplina de "História e Cultura Afro-brasileira e Indígena" seja inserida nos currículos escolares brasileiros, raramente os textos considerados não-canônicos são difundidos nas escolas. Isso acontece devido ao desconhecimento dos educadores a respeito desses escritos não pertencentes à literatura clássica. A falta de informação dos docentes sobre essa literatura não pertencente aos cânones resulta na resistência desse grupo em trabalhar com a literatura negra nas salas

3 O escritor Cuti, cujo nome é Luiz Silva, nasceu em Ourinhos, São Paulo, no dia 31 de outubro de 1951. É formado em Letras pela Universidade de São Paulo, mestre Teoria da Literatura e doutor em Literatura Brasileira pela Unicamp. 
de aula brasileiras ${ }^{4}$.

Todavia, o grande problema em se trabalhar apenas com os clássicos é que, na maioria das vezes, estes textos estão contaminados pela cultura eurocêntrica e, portanto, a população afrodescendente tornase praticamente invisível nessas textualidades. Os poucos personagens negros que transitam pelos clássicos brasileiros são representados de forma negativa nas narrativas, como se fossem responsáveis por todas as mazelas da sociedade brasileira.

Em contraposição à literatura canônica, a poesia forte de Cuti (2011), objeto desta pesquisa, expõe de forma dura as feridas causadas por décadas de escravidão e, da mesma forma, joga luz nas relações raciais, mostrando a discriminação presente na sociedade, mas disfarçada sob a máscara da democracia racial. Por esses aspectos, a poesia desse autor convidou-nos a entrar no universo literário e, estimulou-nos a investigar os propósitos dessa literatura. Do mesmo modo, instigou-nos a pesquisar autores que abordam o tema do preconceito racial.

Com essas pesquisas, em âmbito analítico, buscamos contribuir paraque pesquisadores de diversas universidades ${ }^{5}$ reflitam sobre a assimetria das relações raciais e suas consequências para a sociedade brasileira e,dessa maneira, revejam seus posicionamentos sobre esse tema.

Nesse sentido, pretendemos, no desenvolvimento desse artigo, através de pesquisa bibliográfica, responder as seguintes indagações como problematização de pesquisa: a que elementos o poeta Cuti (2011) recorre para construir a identidade negra na sua poesia? Quais os procedimentos adotados por esse autor para afirmar a identidade negra? Que recursos o escritor utiliza para combater os estereótipos atribuídos ao negro pelo branco?

Para alcançar os objetivos e propósitos desta investigação científica, seguimos alguns passos: o primeiro deles foi analisar a poesia de Cuti (2011), buscando perceber os sentimentos mais profundos do eu-lírico, a visão de mundo desse poeta, a relação do eulírico com ele próprio e com o outro. Após, relacionamos os conceitos e definições de literatura negra presentes nas pesquisas de Bernd (1988), Duarte (2005), Ianni (1988) e Cavalcante (2017), aos estudos de Bento (2002) e Munanga (2006) sobre preconceito racial no Brasil, eàs pesquisas de Hall (1996), a respeito das identidades, com a poesia de Cuti (2011), apontando em que aspectos a poesia desse autor comprova ou confronta esses estudos.

Na etapa seguinte, fizemos a análise da poesia de Cuti (2011), procurando observar os pontos de vista do eu-lírico, a sua intencionalidade, os símbolos e os significados pretendidos. Da mesma forma, analisamos semanticamente os termos recorrentes na poesia desse autor. Essas observações estão transcritas em três seções: na primeira, intitulada "A poesia engajada de Cuti”, discorremos sobre a relevância da inclusão da literatura negra no contexto escolar. A segunda intitula-se "A afirmação da identidade negra”,nessa seção identificamos a que elementos o poeta recorre para construir a identidade negra e também verificamos os procedimentos adotados por esse escritor para afirmá-la. Na terceira seção, intitulada "O combate aos estereótipos", averiguamos os recursos utilizados por Cuti (2011) para combater os estereótipos atribuídos ao negro pelo branco. Ao seguir esses procedimentos, buscamos atingir o objetivo a que nos propomos a

4 Nesse grupo encontrava-me inclusa. Meu contato com a literatura negra se deu na disciplina de literatura negra, no curso de especialização. O encontro com essa literatura engajada propiciou-me conhecer os sentimentos e percepções dessa população. 5 Aqui, eu me incluo como uma das pesquisadoras interessadas na linha de pesquisa de literatura e cultura afro-brasileira. 
cumprir, que é compreender como ocorre a construção da identidade negra na poesia de Cuti (2011).

\section{A POESIA ENGAJADA DE CUTI}

\section{Conforme Cuti:}

O sujeito étnico branco do discurso bloqueia a humanidade da personagem negra, seja promovendo sua invisibilidade, seja tornando-a mero adereço das personagens brancas ou apetrecho de cenário natural ou de interior, como uma árvore ou um bicho, um móvel ou qualquer utensílio ou enfeite doméstico. Aparece mas não tem função, não muda nada, e se o faz é por mera manifestação instintiva, por um acaso. Por isso tais personagens não têm história, não têm parentes, surgem como se tivessem origem no nada. A humanidade do negro, se agride a humanidade do branco, é porque esta última se sustenta sobre as falácias do racismo.(CUTI, 2010, p. 89)

Nesse aspecto, a literatura canônica ajuda a disseminar o preconceito racial, já que manipulando artisticamente a palavra, ela retrata visões de mundo e influencia atitudes e comportamentos. Segundo Duarte:

\begin{abstract}
A literatura costuma ser definida, antes de tudo, como linguagem, construção discursiva marcada pela finalidade estética. Tal posição ancora-se no formalismo inerente ao preceito kantiano da 'finalidade sem fim' da obra de arte. Todavia, outras finalidades, para além da fruição estética, são também reconhecidas e expressam valores éticos, culturais, políticos e ideológicos. A linguagem é, sem dúvida, um dos fatores instituintes da diferença cultural no texto literário. (DUARTE, 2014, p. 26)
\end{abstract}

Portanto, por meio da literatura, estereótipos e crenças podem ser reforçados ou rechaçados. Nesse sentido, a literatura afro-brasileira surge para fortalecer a cultura negra e combater a imagem pejorativa do negro, através do resgate de suas origens e de suas lutas que foram apagadas pela história oficial.

Ianni entende que:

São várias e difíceis as operações 'ideológicas' que os escritores negros realizam para desanuviar o ambiente, mapear as situações presentes, resgatar a história, desvendar a sua matéria de criação, formular os seus temas, pesquisar as suas linguagens, alcançar a transparência na relação do seu eu individual com o seu eu coletivo. A cultura e a ideologia dominantes escondem muito, praticamente tudo: história incruenta, escravidão açucarada, democracia racial etc. (IANNI, 1988, p. 93)

O fortalecimento da cultura negra, por meio da literatura, só foi possível paulatinamente à tomada de posição do negro no discurso poético. afrodescendente deixou de ser aquele de quem se fala e passou a ser a voz que fala na poesia afro-brasileira. O surgimento de um eu-lírico-que-se-quer-negro fez com que os escritores descendentes de africanos assumissem o papel de porta-voz de seu povo e, em nome dessa população passaram a denunciar o preconceito e o processo de depreciação a que a sua etnia vem sendo submetida há muito tempo. Conforme Taylor (1994, p. 41-42, apud Munanga 2006, p.28)
A tese é a de que nossa identidade é parcialmente formada pelo reconhecimento ou por sua ausência, ou ainda pela má percepção que os outros têm dela: uma pessoa ou um grupo de pessoas pode sofrer um prejuízo ou uma deformação real se as pessoas ou as sociedades que os rodeam (sic) lhes devolvem uma imagem limitada, depreciativa ou desprezível deles mesmos. O não reconhecimento ou o reconhecimento inadequado pode causar prejuízo ou uma deformação de opressão, ao aprisionar alguns num modo de ser falso, deformado e reduzido.

Nessa perspectiva, observamos que a literatura afro-brasileira deve ser divulgada no contexto escolar, visto que ajuda a reforçar o sentimento de pertencimento de estudantes negros, valorizando a sua autoimagem e, contrapondo-se, assim, aos métodos que tentar inferiorizá-la pela valorização exagerada do biotipo branco na literatura clássica.

Nesse contexto, a poesia de Cuti (2011) é uma arma poderosa contra os paradigmas que estigmatizam o negro brasileiro, pois, com sua poesia combativa, esse autor denuncia e luta contra o preconceito racial, da mesma forma que busca construir uma identidade negra para representar os 
descendentes de escravizados, a partir de sua visão de negro em uma sociedade branca. Esse poeta ressalta o orgulho de ser negro e afirmando-se como tal, exige respeito para a comunidade a qual representa.

A poesia de engajamento de Cuti (2011) mostra os dramas pelos quais passam os afrodescendentes, através de um ponto de vista negro. Levando os leitores a refletir sobre as diversas situações vivenciadas pelo negro brasileiro e, dessa forma, proporciona discussões sobre as relações raciais no contexto escolar.

Nesse sentido, a difusão dessa literatura engajada nas escolas colabora para o desenvolvimento de uma educação para as relações étnico-raciais, pautada no respeito às diferenças e no conhecimento da história e cultura afro-brasileira, presentes na poesia de Cuti (2011). Essa educação voltada para as relações étnico-raciais, ajudará o estudante a perceber os paradigmas eurocêntricos que desqualificam e desprezam as contribuições dos descendentes de escravos na formação da nação brasileira. Também, ajudará o discente a identificar, criticar e desconstruir o discurso do opressor, que se fundamenta no racismo, para construir outros discursos, livres desse preconceito.

Uma vez que a sociedade brasileira é marcada pela diferença, é necessário que os educadores entendam que a escola é o lugar onde as diversas culturas e etnias se entrecruzam. Portanto, é nesse ambiente que se deve estabelecer um diálogo entre esses sujeitos, a fim de que se possa dar início à construção de uma sociedade com igualdade de condições para todos.

\section{A AFIRMAÇÃO DA IDENTIDADE NEGRA}

A poesia negra surge com a tomada de posição do sujeito da enunciação. A mudança de posição marca a passagem da alienação do negro à sua conscientização. Essa tomada de consciência traz como consequência a afirmação de sua condição negra, que ocorre por meio de um eu-enunciador-que-se-quernegro e que busca uma identidade para representá-lo na poesia. Conforme Bernd (1988, p. 50)

\begin{abstract}
Esse eu lírico em busca de uma identidade negra instaura um novo discurso - uma semântica do protesto - ao inverter um esquema onde ele era o Outro: aquele de quem se condoíam ou a quem criticavam. Passando de outro a eu, o negro assume na poesia sua própria fala e conta a história de seu ponto de vista. Em outras palavras: esse eu representa uma tentativa de dar voz ao marginal, de contrapor-se aos estereótipos (negativos e positivos) de uma literatura brasileira legitimada pelas instâncias de consagração.
\end{abstract}

Nesse sentido, o negro assume na poesia a sua própria fala e conta a sua história do seu ponto de vista. Assim, expõe as suas feridas e denuncia a sua posição de oprimido. Dessa forma, revela uma face da sociedade até então omitida pela literatura brasileira. Para Bernd (1988), essa fala do eu-enunciador na poesia se faz como parte da vivência do eu-lírico que se assemelha à experiência da realidade do poeta. Porém, isso não significa que os textos de literatura negra sejam, na sua totalidade, baseados na realidade da vivência do poeta, essa experiência de vida pode ser fictícia. No entanto, nos escritos essa experiência se manifesta no sentido real e geralmente vai na contramão do discurso dominante.

Por contestarem os valores representados pela cultura dominante e mostrarem outros aspectos da sociedade não revelados pela literatura instituída, esses textos promovem a ruptura com a escrita ditada pelos brancos. Por isso, esses textos são chamados de contraliteratura, assim definidos por Bernd (1988, p. 43 e 44):

Caracterizando-se por uma postura crítica no
interior do campo literário instituído, a
contraliteratura se estrutura como contestação
sistemática dos valores representados pela
cultura dominante.
Os textos da contraliteratura quase sempre se 
afastam de uma tradição de construção eufórica ou ufanista que encobrem a realidade. Organizando-se como contradição a esse tipo de retórica grandiloquente, que camufla os aspectos deprimentes da sociedade como miséria, guerra, racismo, subdesenvolvimento, etc., ela abre uma brecha para o aparecimento da realidade oculta, permitindo ao mesmo tempo o resgate da imagem real do homem e a emergência de um discurso de resistência à opressão.

A ruptura com a literatura instituída ocorre, na medida em que, por meio do discurso poético, o eu-lírico rebate a ideia de democracia racial, tão difundida na sociedade, revelando que este conceito, na verdade, não passa de uma forma de camuflar o racismo e a exclusão a que o afrodescendente está exposto. Essas formas de segregação são denunciadas por Cuti no poema Negroesia:

Enxurrada de mágoas sobre os
paralelepípedos
por onde passam carroções de palavras duras
com seus respectivos instrumentos de tortura.
entre silêncios
augúrios de mar e rios
o poema acende seus pavios
e se desata
do vernáculo que mata
ao relento das estrofes
acolhe os risos afros
embriagados
de esquecimento e suicídio
no horizonte do delírio
e do âmago do desencanto contesta as
máscaras
lançando explosivas metáforas pelas brechas
dos poesídios
contra o arsenal do genocídio. (CUTI, 2011,
p. 149)

Na primeira estrofe do poema, o poeta revela os dramas causados por séculos de escravidão e relembra o passado escravocrata de sua etnia. Também denuncia o racismo explícito manifestado por “palavras duras”, que ferem tal qual os instrumentos de tortura utilizados no período escravagista. Essas palavras preconceituosas servem para afirmar estereótipos e crenças que inferiorizam o negro e, assim, perpetuam a sua condição de oprimido. Esse discurso de dominação está representado na palavra “poesídios”, um neologismo criado por Cuti (2011). Para Cavalcante(2017), esse neologismo refere-se à poesia que retrata o negro de forma depreciativa, ou melhor, que reflete o discurso instituído sobre o negro.

Em contrapartida, o eu-enunciador enfrenta o opressor utilizando as mesmas armas usadas pelo dominador para rebaixálo, no caso, as palavras e, em oposição aos poesídios cria o neologismo “negroesia”, que dá título ao poema. Segundo autora citada anteriormente,esse neologismo corresponde à poesia comprometida com a construção da memória e da identidade negra, isto é, a poesia afro-brasileira.

Nessa poesia, o eu-enunciador-que-sequer-negro combate o preconceito e a discriminação. Os versos "o poema acende seus pavios / e se desata / do vernáculo que mata” revelam a força e a determinação da poesia afro-brasileira, na busca pela redefinição da identidade negra.

Cabe salientar que, quando o eu-lírico assume essas lutas, ele está, também, marcando a sua posição no mundo e afirmando a sua identidade negra. Portanto, ao apoderar-se da palavra, o eu-enunciador deseja sair da obscuridade e revelar o seu modo negro de ver e sentir o mundo. Conforme Bernd (1988, p. 77)

\begin{abstract}
A enunciação em primeira pessoa revela a determinação do poeta de desvencilhar-se do anonimato e da 'invisibilidade' a que o relegou sua condição de descendentes de escravos ou de ex-escravos e, mesmo após a Abolição, sua situação de estranhamento em uma sociedade que não o convocou a participar em igualdade de condições.
\end{abstract}

Nessa direção, o enunciador determina a intenção do sujeito textual, que é de tirar a sua comunidade da invisibilidade, através da expressão de sua situação na sociedade para que busquem reagir contra essa realidade. 
Notamos esse propósito no poema "Tristes trópicos" (CUTI, 2011, p. 150), abaixo reproduzido:

$$
\begin{aligned}
& \text { Tristes trópicos } \\
& \text { depois de escravo } \\
& \text { pensei que podia } \\
& \text { garantir ao menos } \\
& \text { em paz } \\
& \text { a comida } \\
& \text { o coma veio logo } \\
& \text { depois da imensa fer } \\
& \text { desvendar a fera q } \\
& \text { cravar-lhe os dentes } \\
& \text { o que pude } \\
& \text { mas ela continua: } \\
& \text { bebe sangue } \\
& \text { mar } \\
& \text { rio } \\
& \text { açude }
\end{aligned}
$$$$
\text { depois da imensa ferida }
$$$$
\text { desvendar a fera que nos consome e ilude }
$$$$
\text { cravar-lhe os dentes na carne }
$$

O eu-enunciador expõe, nos versos da primeira estrofe, a sua desilusão por ter sido rechaçado pela sociedade branca. Marca a sua posição utilizando a primeira pessoa do singular, porém, não fala somente em seu nome. O eu-lírico, neste discurso, é o portavoz de uma comunidade negra que se encontra marginalizada. No verso "desvendar a fera que nos consome e ilude", o pronome "nós" revela que a exclusão social não é um drama particular do eu-lírico e, sim, de toda a comunidade que ele representa. Percebemos, também, a intenção do eu-enunciador de conscientizar esse grupo de que a igualdade racial apregoada pelo grupo opressor não passa de uma tentativa de mascarar a realidade, pois, na verdade, a exclusão social desse grupo étnico continua avançando impiedosamente, o que pode ser observado nos seguintes versos "mas ela continua: / bebe sangue / mar / rio / açude".
Além de denunciar a exclusão social e o preconceito, a literatura negra é território de combate contra os estereótipos e tudo que tenta inferiorizar o negro. Nela, as narrativas e os versos são envolvidos politicamente com histórias, e há a retomada dos elementos da memória e das tradições passadas dos povos africanos e afro-brasileiros (Duarte, 2005), na procura de reafirmar a identidade negra e de modificar a visão do branco sobre o negro.

\section{O COMBATE AOS ESTEREÓTIPOS}

A visão estereotipada do branco sobre o negro desencadeou um processo de inferiorização do afrodescendente na sociedade. Isso fez com que esse grupo se afastasse de suas origens com intuito de ser incluso na sociedade branca. $\mathrm{O}$ euenunciador dessa literatura, ciente de que a inclusão não se fará dessa forma, busca conscientizar essa comunidade da necessidade de afirmação da identidade negra como caminho para desconstruir os estereótipos e conquistar espaços. Portanto, o eu-lírico conclama a sua comunidade a resgatar as origens, reapropriando-se, assim, de referentes perdidos. Segundo Bernd (1988, p. 42 e 43)

$$
\begin{aligned}
& \text { (...) a função da literatura é interpretar a } \\
& \text { consciência coletiva e nacional e convocar a } \\
& \text { uma solidariedade ativa. A situação do } \\
& \text { escritor, muitas vezes afastado } \\
& \text { espiritualmente de sua comunidade de } \\
& \text { origem, confere-lhe os meios de exprimir } \\
& \text { uma comunidade potencial, para a qual } \\
& \text { vislumbra uma função de reapropriação dos } \\
& \text { referentes perdidos. }
\end{aligned}
$$

Nesse sentido, a reapropriação dos referentes perdidos, defendida na literatura negra, é essencial para combater a ideologia do "branqueamento". Segundo essa ideologia, o branco deveria ser o modelo a ser seguido pelo negro. Negando, assim, a sua identidade negra. O negro, para ser aceito na sociedade, deveria imitar as características físicas, morais e culturais do branco (BERNDT, 1988). No entanto, o eu- 
lírico se opõe a esse pensamento e combate os valores culturais do branco, ao afirmar que a comunidade negra deve assumir-se como tal, resgatando as suas características físicas e culturais, já que "as identidades culturais são pontos de identificação, os pontos instáveis de identificação ou sutura, feitos no interior dos discursos da cultura e da história" (Hall, 1996, p.70).

Notamos a oposição a essa ideologia nos poemas "Ferro" e "Trincheira", reproduzidos na sequência:

Ferro
Primeiro o ferro marca
a violência nas costas
Depois o ferro alisa
a vergonha nos cabelos
Na verdade, o que se precisa
é jogar o ferro fora
é quebrar todos os elos
dessa corrente
de desesperos (Cuti, 2011, p. 148)

Observamos no poema que a palavra "ferro" apresenta dois significados diferentes. Nos versos "primeiro o ferro marca / a violência nas costas" denomina o instrumento utilizado pelos proprietários para marcar a posse do escravo, tirando,assim, a humanidade do escravizado, reduzindo o sujeito negroa objeto com valor monetário.

A segunda ocorrência "Depois o ferro alisa / a vergonha nos cabelos", faz alusão ao apetrecho utilizado para modificar uma característica identitária marcante desse grupo étnico. Podemos entender essa alteração na característica étnica como uma consequência da internalização da imagem negativa atribuída a essa população pelo grupo dominante. Conforme Munanga (2006,p. 6) "durante gerações a sociedade branca tem feito deles4 uma imagem depreciativa à qual alguns deles não tiveram força para resistir, pois a introjetaram e criaram uma auto-depreciação que hoje se tornou uma das armas mais eficazes de sua própria opressão.”.

Nesse aspecto, o eu-enunciador faz um apelo a sua comunidade para que se liberte de todos os mecanismos que tentam inferiorizá-la. Isso pode ser observado nos seguintes versos "Na verdade, o que se precisa / é jogar o ferro fora / é quebrar todos os elos / dessa corrente / de desesperos".

Em "Trincheira", reproduzido abaixo, percebemos a intenção do eu-lírico de denunciar a desigualdade racial e afirmar uma imagem positiva do negro.

Trincheira
Falaram tanto que nosso cabelo era ruim
que a maioria acreditou
e pôs fim
(raspouqueimoualisourelaxoucanecaloucuras)
ainda bem que as raízes continuam intactas
e há maravilhosos pelos
crespos
conscientes
no quilombo das regiões
íntimas
de cada um de nós. (Cuti, 2011, p. 149)

Notamos que o cabelo crespo, considerado símbolo da identidade negra, é caracterizado como "ruim", inferior. Em contraposição, o cabelo liso, predominante na população branca, é tido como superior. Essa imagem desvalorizada, atribuída pelo discurso do opressor, foi introjetada pelo oprimido. Para sair dessa condição desprestigiada, o afrodescendente tenta aniquilar essa marca identitária "raspou", "queimou”, "alisou”, "relaxou”, negando, dessa forma, a sua identidade negra.

Por outro lado, o eu-lírico enfatiza que apesar do grupo opressor tentar apagar as marcas da identidade negra por meio de um discurso que inferioriza o afrodescendente, a 
populaçãoafro-brasileira que saiu da alienação resiste e afirma a sua negritude.

Assim, oeu-enunciador-que-se-quernegro rejeita a identidade estereotipada que lhe é atribuída pelo outro. Para contrapor-se a essa imagem negativa, o eu-líricoressalta e valoriza as características de sua etnia. A reversão das características negativas em positivas é resultado da conscientização desse grupo a respeito do processo de desterritorialização a que foram sujeitados. Segundo Bernd (1988, p. 42)

(...) Entendendo-se território como o conjunto de projetos e de representações dos indivíduos, desterritorialização corresponde ao sentimento de perda dessas referências. Neste sentido, a literatura negra se organiza como revide aos movimentos contínuos de destruição dos territórios culturais negros e como tentativa de resgatá-los para investi-los de novas significações;

$O$ resgate e a ressignificação de elementos da cultura negra são armas poderosas para essa população marcar a sua presença negra em uma sociedade de valores brancos. No poema "Sou negro" (Cuti, 2011, p. 145), percebemos o desejo do eu-lírico de reverter estereótipos em atributos positivos:

Sou negro

Sou negro

Negro sou sem mas ou reticências

Negro e pronto!

Negro pronto contra o preconceito branco

O relacionamento manco

Negro no ódio com que retranco

Negro no meu riso branco

Negro no meu pranto

Negro e pronto!

Beiço

Pixaim

Abas largas meu nariz

Tudo isso sim

- Negro e pronto! -

Batuca em mim

Meu rosto

Belo novo contra o velho belo imposto

\author{
E não me prego em ser preto \\ Negro pronto \\ Contra tudo o que costuma me pintar de sujo \\ Ou que tenta me pintar de branco \\ Sim \\ Negro dentro e fora \\ Ritmo - sangue sem regra feita \\ Grito - negro - força \\ Contra grades contra forças \\ Negro pronto \\ Negro e pronto
}

A repetição da palavra negro ao longo do poema soa como um grito de libertação do afrodescendente, frente a uma sociedade opressora que insiste em negar a identidade dessa etnia e, que usa a palavra "negro" como instrumento para rebaixá-lo.

Porém, a reiteração desse termo no texto mostra o orgulho do eu-lírico por pertencer a essa comunidade. Já a ênfase nas características físicas desse grupo "Beiço / Pixain / Abas largas meu nariz" tem por finalidade marcar seus atributos físicos e expor o modo depreciativo de representação do descendente de escravos "Contra tudo o que costuma me pintar de sujo / Ou que tenta me pintar de branco".

Sob esse prisma, no poema "Eu negro"(CUTI, 2011, p. 146), abaixo transcrito, observamos a intenção do eulírico de desconstruir a imagem negativa imputada ao negro, além de denunciar a sua exclusão social. Para modificar essa representação o eu-lírico utiliza como recurso a exaltação da força e da resistência dessa etnia.

Eu negro

Areia movediça na anatomia da miséria

Pano-pra-manga na confecção apressada de humanidade

Chaga escarnada contra o risco atômico dos ladrões

Espinho nos olhos do aquecimento feliz de ontem

Eu 


Eu feito de sangue e nada
De Amor e Raça
De alegrias explosivas no corpo do
sofrimento e mágoa
Ponto de encontro das reflexões vacilantes da
História
Esperança fomentada em fome e sede
Eu

A sombra decisiva dos iluminismos cegos

O câncer dos humanismos desumanos

$\mathrm{Eu}$

Eu feito

De Amor e Raça

De alegrias incontroláveis que arrebentam as rédeas dos sentimentos egoístas

\section{Eu}

Que dou vida às raízes secas das vegetações brancas

Eu

Ébano que não morreu no temporal das agressões doentias

Força que floresceu no tempo das fraquezas alheias

Feito de Amor e Raça

E alegrias explosivas.

O eu-enunciador, sob a perspectiva interna, mostra a vivência do negro na sociedade e a sua situação de abandono e anonimato. O título do poema "Eu negro" nos mostra que o calvário vivenciado pelo eu-lírico não é uma experiência particular, ela se estende a toda a comunidade negra. Entretanto, o afrodescendente resiste a todas as adversidades, conforme expresso nos versos"Ébano que não morreu no temporal das agressões doentias / Força que floresceu no tempo das fraquezas alheias" e se faz essencial na sociedade branca "Eu / Que dou vida às raízes secas das vegetações brancas”.

\section{CONSIDERAÇÕES FINAIS}

O eu-enunciador-que-se-quer-negro presente na literatura afro-brasileira surgiu da passagem da alienação à conscientização do negro. Ao tomar consciência de sua situação de dominação na sociedade, o escritor negro decide tomar posse da palavra e romper com a literatura canônica, onde o negro era representado pela perspectiva do outro.

O objetivo do poeta negro, ao dar voz ao eu-enunciador, é desconstruir a imagem estereotipada do negro construída durante anos e afirmar a sua identidade negra, construída pela perspectiva interna. Nessa direção, a poesia afro-brasileira se caracteriza pela busca da identidade negra.

Na poesia de Cuti (2011),identificamos a intenção de construir a imagem de seu grupo étnico através da exaltação da resistência e da força desse sujeito que conseguiu sobreviver à mácula da escravidão. Com a mesma finalidade, o poeta enumera as características físicas diferenciais (nariz de abas largas, beiço, pele negra, cabelo pixaim), dessa forma, afirma a identidade negra pela valorização do fenótipo. Por sua vez, encontramos na poesia de Cuti(2011) uma crítica à tentativa de transformação das características étnicas. O poeta declara que a afirmação da identidade negra está nas características diferenciais. Com essa visão, o eu-lírico da poesia de Cuti conclama sua comunidade negra a resgatar as suas origens e a se reapropriar dos referentes perdidos.

Outra característica marcante é o empenho em denunciar a discriminação, o preconceito e a exclusão social a que estão submetidos os afrodescendentes brasileiros. Dessemodo, podemos afirmar que a poesia de Cuti(2011) é semelhante a um campo de batalha. Nesse cenário de guerra de um lado está "eu/nós" (comunidade negra) e do outro "eles" (o branco opressor), sendo que os alvos a serem combatidos pelo poeta são a imagem negativa do negro, o preconceito e a exclusão social.

Nesses escritos, notamos também a reiteração da palavra "negro" em demasia, apontando o propósito do autor de dar 
visibilidade a essa comunidade de descendentes de escravos. $\mathrm{O}$ poeta profere $\mathrm{a}$ palavra "negro" com tanta intensidade, que ela passa a ser audível. Assim, seja por meio de combate, de reivindicação, ou de imposição, Cuti (2011) constrói a identidade negra na poesia contemporânea e exige o seu reconhecimento pelas suas especificidades.

\section{REFERÊNCIAS}

BENTO, M. A. S.Branqueamento e branquitude no Brasil. In: . Psicologia social do racismo - estudos sobre branquitude e branqueamento no Brasil. [S.l.]: Vozes, 2002. P. $25-28$.

BERND, Z. Introdução à literatura negra. São Paulo: Brasiliense, 1988. ISBN 85-11-18130-X. . Negritude e literatura na América Latina. Porto Alegre: Mercado Aberto, 1988.

\section{CAVALCANTE, F. C. L. Literatura afro-} brasileira: um processo de afirmação identitária e de resistência negra na poesia de Cuti. In: . Opiniães: Revista dos alunos de Literatura Brasileira / Faculdade de Filosofia, Letras e Ciências Humanas da Universidade de São Paulo. Departamento de Letras Clássicas e vernáculas - no 10 (2017) - São Paulo: FFLCH, p. 86 - 102, 2017.

CUTI, L. S. Literatura negro-brasileira. São

Paulo: Selo Negro, 2010. .Seleção de Poemas. In:

Antologia de poesia afro-brasileira: 150 anos de consciêncianegra no Brasil. Belo Horizonte: Mazza, p. 141 - 150, 2011.

DUARTE, E. de A. Literatura, política, identidades. [S.l.]: FALEUFMG, 2005.

HALL, S. Identidade cultural e diáspora.

Revista do Patrimônio Histórico e Artístico

Nacional, IPHAN, Rio de Janeiro, p. 68 - 75, 1996.

IANNI, O. Literatura e consciência. Revista do Instituto de Estudos Brasileiros. São Paulo, n.

28, p. 91 - 99, 1988. Disponível em:

http://www.revistas.usp.br/rieb/article/

view/70034. Acesso em: 5/12/2017.

MUNANGA. K. Construção da identidade negra no contexto da globalização. In:

Vozes (além) da África. Juiz de Fora: Ed. UFJF, p. $19-41,2006$.

Diversidade, identidade,

etnicidade e cidadania. Disponível em:

http://www.acaoeducativa.org.br/fdh/?p=1540.

Acesso em: 5/10/2018. 